\title{
IS PARENTERAL ADJUNCT ANTI-THROMBOTIC THERAPY WITH THROMBECTOMY NEEDED FOR PRIMARY PERCUTANEOUS CORONARY INTERVENTION IN ST ELEVATION MYOCARDIAL INFARCTION?
}

R Showkathali, S Roshanzamir, D Baskaran, 0 Cook, J R Davies, R K Aggarwal, P A Kelly, K H Tang, G J Clesham, R A Gamma, R Jagathesan, J W Sayer The Essex Cardiothoracic Centre

doi:10.1136/heartjnl-2013-304019.62

Introduction Adjunct anti-thrombotic therapies (ATT) such as Glycoprotein 2b3a inhibitors (GPI) and bivalirudin are shown to improve clinical outcome in primary percutaneous coronary intervention (PPCI). However, most of the studies related to this were done prior to high dose loading of clopidogrel $(600 \mathrm{mg})$ and without the routine use of thrombectomy device. We aimed to compare the outcome between patients who had thrombectomy and parenteral ATT with those who had thrombectomy with no ATT during PPCI in our unit.

Methods We included all patients undergoing PPCI in our unit from September 2009 to November 2011. All patients during the study period were loaded with Aspirin $300 \mathrm{mg}$ and Clopidogrel $600 \mathrm{mg}$ prior to angiography. Unfractionated Heparin (UFH) is used routinely for all PPCI in our unit immediately after angiography, irrespective of whether GPI or bivalirudin is used as ATT. This is in response to the HORIZONS AMI study analysis, which showed use of UFH reduced the risk of stent thrombosis in both arms of the study. Operators used ATT at their own discretion. We defined non-CABG bleeding as anyone requiring at least one unit of red cell transfusion.

Results Of the 1471 patients who underwent PPCI during the study period, we excluded 408 (27.7\%) patients who did not have thrombus aspiration (TA) during their procedure. The remaining patients $(n=1063)$ were divided into two groups according to whether they had ATT or not (ATT grp: TA+UFH+ATT and UFH grp: TA+UFH). In the ATT group 397 (48.6\%), 395 (48.4\%) and 25 (3.4\%) patients had abciximab, bivalirudin and combination therapy of both respectively. There were more elderly patients and women in the UFH group when compared to ATT group, but all other baseline and procedural characteristics were similar in both groups (table 1).

In-hospital mortality, 30-day mortality, non-CABG major bleeding and stent thrombosis rates were similar in both groups (UFH vs ATT) (table 2).

Table 1 Baseline and procedural characteristics of both groups

\begin{tabular}{llll}
\hline $\mathbf{n}(\%)$ & $\begin{array}{l}\text { TA+adjunct+UFH } \\
\text { (n=817) }\end{array}$ & $\begin{array}{l}\text { TA+UFH } \\
\text { (n=246) }\end{array}$ & p Value \\
\hline Age in years (mean \pm SD) & $63 \pm 13.3$ & $67 \pm 12.9$ & 0.0008 \\
Age $>75$ years & $171(20.9)$ & $68(27.6)$ & 0.03 \\
Female & $189(23.1)$ & $79(32.1)$ & 0.006 \\
Cardiogenic shock & $65(8)$ & $17(6.9)$ & 0.7 \\
Diabetes & $83(10.2)$ & $35(14.2)$ & 0.08 \\
Pre-procedural TIMI 0/1 flow & $679(83.1)$ & $202(82.1)$ & 0.7 \\
Single vessel PCI & $747(91.4)$ & $224(91.1)$ & 0.8 \\
DES & $489(59.9)$ & $146(59.3)$ & 0.9 \\
LAD PCI & $371(45.4)$ & $103(41.9)$ & 0.3 \\
\hline
\end{tabular}


Table 2 Clinical outcome between the two groups

\begin{tabular}{lccc}
\hline $\mathbf{n}(\%)$ & $\begin{array}{l}\text { TA+ATT+UFH } \\
(\mathbf{n = 8 1 7})\end{array}$ & $\begin{array}{l}\text { TA+UFH } \\
(\mathbf{n = 2 4 6 )}\end{array}$ & $\mathbf{p ~ V a l u e}$ \\
\hline In-hospital mortality & $30(3.7)$ & $13(5.3)$ & 0.3 \\
30-day mortality & $43(5.3)$ & $18(7.3)$ & 0.2 \\
Non-CABG bleed & $20(2.5)$ & $3(1.2)$ & 0.3 \\
Acute stent thrombosis (<24 hrs) & $1(0.1)$ & $1(0.4)$ & 0.4 \\
30-day stent thrombosis & $3(0.4)$ & $1(0.4)$ & 0.3 \\
\hline
\end{tabular}

On logistic regression analysis of all 1063 patients, there was no effect of ATT on 30-day mortality (OR $0.8,95 \%$ CI 0.4 to $1.6, p$ $0.5)$. The positive predictors of 30 -day mortality were age $>75$ years (OR 4.8, 95\% CI 2.6 to 8.8, p<0.0001), cardiogenic shock (OR 8, 95\% CI 4.2 to $15.4, \mathrm{p}<0.0001)$ and LAD PCI (OR $2.2,95 \%$ CI 1.2 to $4.0, \mathrm{p} 0.008)$ while use of DES was the only negative predictor (OR 0.5, 95\% CI 0.3 to 0.8 , p 0.01).

Conclusions This single centre study shows no significant mortality difference in patients receiving ATT when compared to UFH alone, despite the fact that patients receiving UFH alone were of higher risk. This suggests that the operators' decision to avoid ATT was justified in some patients who had TA. Bleeding risk between the groups was also similar, but this could be related to the definition used in our study. Further studies are needed to clarify the benefit of ATT in PPCI at the present time, with the routine use of more potent or high dose anti-platelet agents and TA. 